\title{
SERUM $\alpha$-HYDROXYBUTYRATE DEHYDROGENASE: A NEW TEST FOR MYOCARDIAL INFARCTION
}

\author{
BY \\ S. B. ROSALKI \\ From the Group Pathological Laboratory, Kingston-upon-Thames, Surrey \\ Received March 17, 1963
}

Determination of serum glutamate-oxaloacetate transaminase (S.G.O.T.) activity and serum lactate dehydrogenase (S.L.D.) activity are already well-established procedures in the diagnosis of myocardial infarction. Since S.G.O.T. may be raised in liver disease also, it has become customary to combine its determination with that of serum glutamate-pyruvate transaminase (S.G.P.T.) activity. This latter enzyme, although increased in liver damage, is usually normal or near normal following infarction (Wróblewski and LaDue, 1956).

The use of S.G.O.T. determination for the detection of myocardial infarction, however, suffers the major disadvantage that elevation following infarction is transient, and unless blood is sampled shortly after the infarct (within four to five days) normal levels are usually observed.

An increase in S.L.D. following infarction is, on the other hand, more prolonged (one to two weeks), and this may help establish a diagnosis in cases first seen several days after the event. The interpretation of its raised activity may nevertheless be difficult because abnormal values can occur in disease of the liver, the kidney, or of skeletal muscle and in neoplasia. Improvement in diagnostic specificity may be obtained by enzyme electrophoresis (Wieme, 1959). This procedure resolves S.L.D. into five components or 'isoenzymes', the fastest moving of which is characteristically increased following myocardial infarction, and remains raised after total S.L.D. activity has returned to normal (Wróblewski, Ross, and Gregory, 1960).

Enzyme electrophoresis is a somewhat complicated and time-consuming procedure, and moreover quantitation is difficult. As an alternative diagnostic procedure, advantage may be taken of the chemical differentiation of the S.L.D. isoenzymes achieved when it was shown that the faster-moving isoenzymes reduced $\alpha$-ketobutyrate more readily than the slower-moving (Rosalki and Wilkinson, 1960). This reduction has been termed serum $\alpha$-hydroxybutyrate dehydrogenase (S.H.B.D.) activity (Elliott and Wilkinson, 1961), and takes place in the presence of reduced nicotinamide-adenine dinucleotide $\left(\mathrm{NADH}_{2}\right)$ according to the following equation:
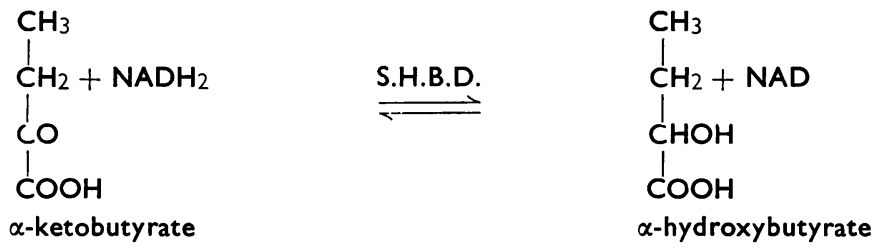

$\alpha$-hydroxybutyrate dehydrogenase (H.B.D.) activity relative to lactate dehydrogenase (L.D.) activity is much greater in the faster-moving S.L.D. isoenzymes, therefore its measurement should be of particular value in the diagnosis of myocardial infarction since it is precisely the faster-moving isoenzymes that are preferentially increased in cardiac muscle damage. 
Preliminary studies (Elliott and Wilkinson, 1961; Konttinen, 1961; Pagliaro and Notarbartolo, 1961; Rosalki, unpublished observations) have shown that S.H.B.D. determination can be useful as a diagnostic aid in myocardial infarction. A further series of observations on its activity following myocardial infarction is presented here, confirming the diagnostic value of determination of this enzyme. For comparison, the results of S.L.D., S.G.O.T., and S.G.P.T. determinations are also presented.

\section{SUBJECTS AND METHODS}

Enzyme determinations were made on 70 in-patients (42 men, 28 women) diagnosed on clinical and electrocardiographic grounds as having sustained a myocardial infarct within the preceding week. All patients were free from clinical evidence of hepatic, renal, neoplastic, or muscular disease.

Initial determinations were carried out more than 12 hours and less than 6 days after the suspected time of infarction. Serial determinations, at intervals not exceeding 48 hours, were carried out on 22 of these patients. Their ages ranged from 36 to 92 years (average 64 years). 17 patients $(24 \%)$ died during their stay in hospital, and necropsy performed on 12 of these confirmed recent myocardial infarction in every case.

Enzyme determinations were also made on a further series of 48 patients (including subjects with pulmonary embolism and congestive cardiac failure) on whom a diagnosis of myocardial infarction within the preceding week was originally suspected but not subsequently confirmed, and on 20 patients with hepatic disease.

Blood was obtained without regard to the fasting state and sera were separated from the red cells within two hours of collection. Sera were stored at $4^{\circ} \mathrm{C}$. and examined within five days, previous experiments having shown the enzymes to be stable at this temperature for this period. Hæmolysed specimens were not examined, since hæmolysis results in spurious rise in serum enzyme levels.

Determinations were made of the following enzymes, and the results were expressed in International Units (I.U.) per litre of serum at $25^{\circ} \mathrm{C}$.

(1) Serum lactate dehydrogenase (S.L.D.), normal less than 240.

(2) Serum $\alpha$-hydroxybutyrate dehydrogenase (S.H.B.D.), normal less than 140.

(3) Serum glutamate-oxaloacetate transaminase (S.G.O.T.), normal less than 20.

(4) Serum glutamate-pyruvate transaminase (S.G.P.T.), normal less than 20.

S.L.D. and S.H.B.D. were determined using ultraviolet spectrophotometric procedures (Wróblewski and LaDue, 1955: Rosalki, 1961). S.G.O.T. and S.G.P.T. were determined using the colorimetric methods of Reitman and Frankel (1957).

\section{RESULTS}

Myocardial Infarction. The results of initial enzyme determinations on the 70 patients with proved myocardial infarction are summarized in Table I. Samples were obtained an average of two days after infarction. The one patient with normal S.L.D. activity had blood sampled approximately 13 hours after the suspected time of infarction; her death prevented further sampling; and S.H.B.D. and S.G.O.T. figures showed minimal elevation. S.H.B.D. was abnormal in every patient studied. S.G.O.T. was abnormal in all but five patients: these five did not have initial determinations until the fourth or fifth day following infarction. 28 patients $(40 \%)$ had S.G.P.T. figures above the upper limit of normal.

The values observed suggested that enzyme determination was of some prognostic importance (Tables II and III). In the 17 fatal cases, the mean S.L.D., S.H.B.D., and S.G.O.T. levels observed were 868,646 , and 149 I.U. per litre respectively, compared with values of 665,480 , and 78 in the 53 patients who survived. In those patients with S.L.D. values above 1000 or S.H.B.D. above 750 the mortality was 50 per cent ( 5 of 10 subjects) compared with a mortality of 20 per cent (12 of 60 ) in those with levels below this figure. With S.G.O.T. values in excess of 150 the mortality was 37 per cent ( 6 of 16) compared with a mortality of 20 per cent (11 of 54) for values below this figure.

The age range in each of the above groups was comparable. 
TABLE I

Results of Initial EnZyme Determinations in 70 Patients WITH Proved Myocardial INFARCTION

\begin{tabular}{|c|c|c|c|c|}
\hline & S.L.D. & S.H.B.D. & S.G.O.T. & S.G.P.T. \\
\hline 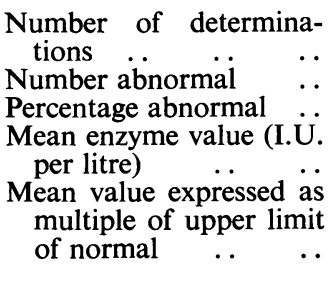 & $\begin{array}{r}70 \\
69 \\
99 \\
714\end{array}$ & $\begin{array}{r}70 \\
70 \\
100 \\
520\end{array}$ & $\begin{array}{l}70 \\
65 \\
93 \\
95\end{array}$ & $\begin{array}{l}70 \\
28 \\
40 \\
\\
27\end{array}$ \\
\hline
\end{tabular}

TABLE II

Relation BETWEen Death FRoM Myocardial INFARCTION AND SERUM ENZYME LEVELS

\begin{tabular}{|c|c|c|c|}
\hline & $\begin{array}{l}\text { S.L.D. } \\
\text { (I.U. per litre) }\end{array}$ & $\begin{array}{l}\text { S.H.B.D. } \\
\text { (I.U. per litre) }\end{array}$ & $\begin{array}{l}\text { S.G.O.T. } \\
\text { (I.U. per litre) }\end{array}$ \\
\hline $\begin{array}{l}\text { Mean levels in } 17 \text { patients } \\
\text { who died . } \\
\text { Mean levels in } 53 \text { patients } \\
\text { who survived }\end{array}$ & $\begin{array}{l}868 \\
665\end{array}$ & $\begin{array}{l}646 \\
480\end{array}$ & $\begin{array}{r}149 \\
78\end{array}$ \\
\hline
\end{tabular}

TABLE III

Relation Between Serum Enzyme Levels and MORTALITY FROM MYOCARDIAL INFARCTION

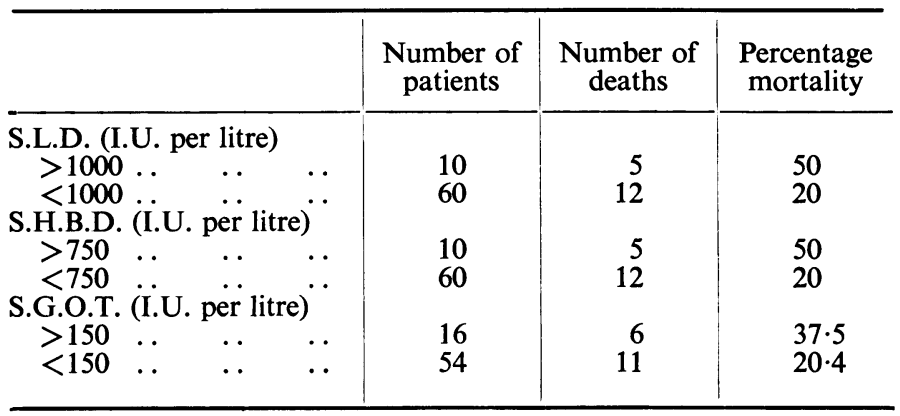

TABLE IV

Results of Serial Enzyme Determinations in 22 Patients With Proved Myocardial Infarction

\begin{tabular}{|c|c|c|c|}
\hline & S.L.D. & S.H.B.D. & S.G.O.T. \\
\hline 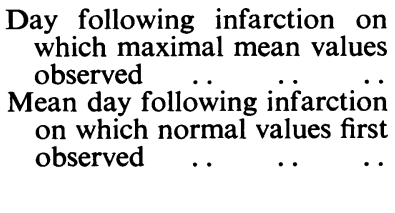 & $\begin{array}{c}11 \cdot 0 \\
(\mathrm{~S} . \mathrm{D} . \pm 3 \cdot 2)\end{array}$ & $\begin{array}{c}13 \cdot 1 \\
(\mathrm{~S} . \mathrm{D} . \pm 3 \cdot 5)\end{array}$ & $\begin{array}{c}5 \cdot 4 \\
(\text { S.D. } \pm 1 \cdot 5)\end{array}$ \\
\hline
\end{tabular}


Table IV shows the time of maximal elevation, and the duration of S.L.D., S.H.B.D., and S.G.O.T. elevation in 22 patients on whom serial determinations were made, all showing raised values for these three enzymes. It can be seen that whereas maximal levels for S.G.O.T. were observed on the first day, S.L.D. and S.H.B.D. peaks were delayed until the second day following infarction. Thus, in those patients sampled on the first day, an increase to peak levels followed by a decrease in the activity of these latter enzymes was frequently observed. S.G.O.T. values returned to normal on average on the fifth day after infarction. S.L.D. did not return to normal until the eleventh day and S.H.B.D. not until the thirteenth day. This difference between the S.L.D. and S.H.B.D. figures is statistically significant $(\mathrm{n}=42, \mathrm{t}=2 \cdot 14, \mathrm{p}=<0 \cdot 05)$. It was however also noted in these serially followed cases, that the lower the peak S.L.D. and S.H.B.D. activity, the quicker did these enzymes return to normal (Table V). No normal S.L.D. levels were observed before the fifth day, nor normal S.H.B.D. levels before the seventh day.

TABLE V

Relation Between Level of Peak S.L.D. AND

S.H.B.D. ACTIVITIES AND DURATION OF Rise

\begin{tabular}{lc|c|c}
\hline & $\begin{array}{c}\text { Peak enzyme } \\
\text { level }\end{array}$ & $\begin{array}{c}\text { No. of } \\
\text { cases }\end{array}$ & $\begin{array}{c}\text { Mean day on } \\
\text { which normal } \\
\text { levels first } \\
\text { observed }\end{array}$ \\
\hline S.L.D. & $<500$ & 7 & $7 \cdot 2$ \\
S.H.B.D. & $>1000$ & 7 & $14 \cdot 8$ \\
& $>375$ & 8 & $10 \cdot 8$ \\
\hline
\end{tabular}

In some patients followed serially but not included in the series above, secondary rises in S.L.D. accompanied by disproportionately smaller degrees of rise in S.H.B.D. were seen towards the end of the second week after infarction. These rises were not accompanied by clinical or electrocardiographic evidence of recurrent infarction.

It seemed possible that this secondary rise was related to ambulation and occurred some 48 hours after the resumption of some degree of physical activity (i.e. sitting out of bed in a chair). A retrospective analysis was therefore made of enzyme levels in 14 patients who resumed some degree of physical activity during the course of serial enzyme determinations. Six patients were made ambulant while S.L.D. levels were still raised: a secondary rise of S.L.D. some 48 hours after ambulation was observed in four. The increase ranged between 7 and 83 I.U. per litre. On a further 8 patients who were mobilized after normal S.L.D. levels were achieved, secondary increases were observed in five. The increases ranged between 15 and 63 I.U. per litre.

Diseases Simulating Myocardial Infarction. Thirty-three patients were studied in whom a diagnosis of myocardial infarction was originally suspected because of chest pain but was not subsequently confirmed on clinical or electrocardiographic grounds. Patients with pulmonary infarction and congestive cardiac failure are considered separately (see Figure). A final diagnosis of angina pectoris or coronary insufficiency was made on all but two of these patients (one diagnosed as pleurisy, the other as exacerbation of duodenal ulcer).

None of them showed any increase of S.L.D. or S.H.B.D. activities. Three raised S.G.O.T. values $(27,21$, and 23 I.U. per litre) were observed. One of these three and one further patient in this group showed increased S.G.P.T. activity (42 and 27 I.U. per litre).

Pulmonary Infarction. Six patients originally suspected of myocardial infarction were finally diagnosed as pulmonary infarction. Slight increases in S.L.D. and S.H.B.D. (263 and 170 I.U. per litre respectively) were found in one patient. Two others showed increased S.G.O.T. (25 and 34 I.U. per litre), one of these also showing increased S.G.P.T. (49 I.U. per litre). 


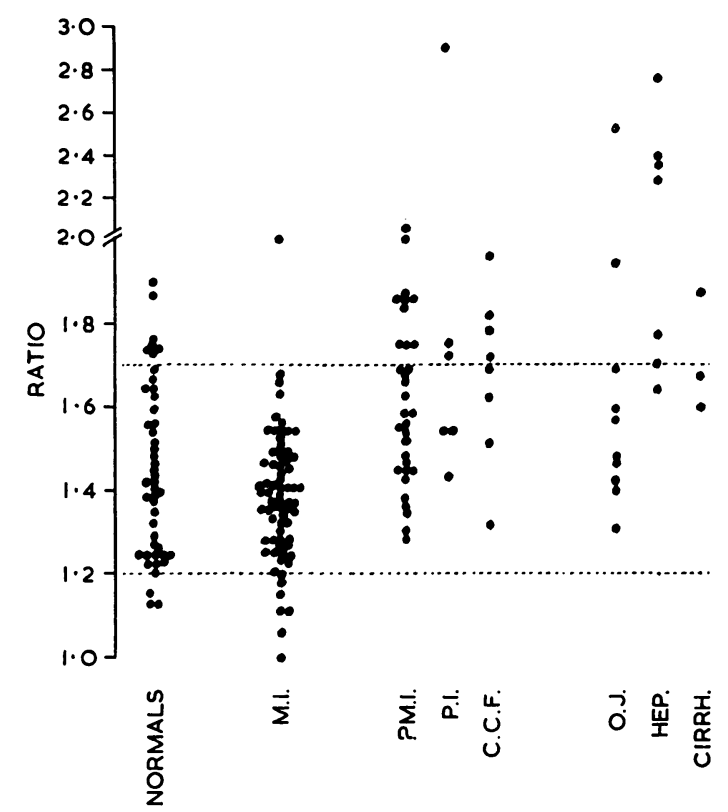

FIGURE.-S.L.D./S.H.B.D. ratios in normal subjects, patients with myocardial infarction(M.I.), suspected but unconfirmed myocardial infarction (?M.I.), pulmonary infarction (P.I.), congestive cardiac failure (C.C.F.), and liver disease (obstructive jaundice, O.J., acute hepatitis, Hep., and hepatic cirrhosis, Cirrh.).

Congestive Cardiac Failure. Nine patients with congestive cardiac failure (including six with hepatomegaly), who had chest pain subsequently shown not to be due to myocardial infarction, were studied. One with hepatomegaly had borderline S.L.D. and S.H.B.D. values (252 and 141 I.U. per litre respectively). Three raised S.G.O.T. values, one with accompanying increased S.G.P.T., were observed.

Liver Disease. Ten cases of obstructive jaundice, 7 of acute hepatitis, and 3 of hepatic cirrhosis were studied. One of the 10 cases of obstructive jaundice showed slightly increased S.L.D. and S.H.B.D. figures (270 and 184 I.U. per litre respectively), all showed increased S.G.P.T. activity, and all but one raised S.G.O.T. Increased S.L.D. activity was observed in all 7 patients with acute hepatitis (5 with infective hepatitis, 2 with glandular fever hepatitis). S.H.B.D. levels were raised in 5. All showed high S.G.O.T. and S.G.P.T. figures. The 3 patients with cirrhosis did not show S.L.D. or S.H.B.D. elevation, although all exhibited raised S.G.O.T. and S.G.P.T. values. The above patients with liver disease were noted to have slightly higher S.L.D./S.H.B.D. ratios (mean $1 \cdot 80$, S.D. \pm 0.41 ) when these were compared with those obtained from 46 normal subjects (mean $1 \cdot 44$, S.D. $\pm 0 \cdot 25$ ), patients with myocardial infarction (mean $1 \cdot 38$, S.D. $\pm 0 \cdot 16$ ), or suspected infarction (mean 1.62, S.D. $\pm 0 \cdot 20$ ). The ratios observed are illustrated in the Figure, together with ratios obtained in the patients with pulmonary infarction and congestive cardiac failure. In the subjects with liver disease the highest S.L.D./S.H.B.D. ratios were observed in the patients with acute hepatitis (mean 2.08).

\section{DiscusSION}

The results obtained indicate that raised S.L.D., S.H.B.D., and S.G.O.T. values will invariably be found in the presence of myocardial infarction, providing care is taken in choosing the time at which samples are obtained. The serial studies showed that the two former were slower to 
reach peak values (second day after infarction) than S.G.O.T. (first day). The one normal S.L.D. value observed in the 70 initial determinations was in blood sampled some 13 hours after the infarction.

It appears wise, therefore, if a single specimen only is to be obtained, to delay sampling to between 24 and 48 hours after infarction; this will then give the greatest likelihood of obtaining abnormal figures for all three enzymes. If a further specimen 24 hours after the first can be examined improved diagnostic precision is to be expected.

Determination of S.L.D. or more especially of S.H.B.D. was superior to determination of S.G.O.T. if initial enzyme determination is delayed beyond the third day. Serial determinations showed that normal levels for the last were obtained on average 5.4 days after the infarction, whereas the corresponding figure for S.L.D. was 11 days and for S.H.B.D., 13 days. These results are in close agreement with those in the recent publication by Elliott and Wilkinson (1962). The four normal S.G.O.T. values at initial sampling on the 70 cases of infarction were all obtained from subjects on whom initial samples were not obtained until the fourth or fifth day after the infarction.

S.H.B.D. determination showed a significant advantage over S.L.D. as far as duration of rise was concerned, and on 6 of 22 patients normal S.H.B.D. activity was not seen until the third or fourth weeks after infarction. None of the 22 patients studied serially showed normal S.L.D. figures before the fifth day nor normal S.H.B.D. before the seventh day. Analysis of the relation between peak values and the duration of increase, however, shows that the lower the peak value, the shorter the duration of the rise.

The mortality figures presented above indicate a relation between severity and serum enzyme levels. It is apparent, therefore, that the less severe an infarct, the more rapid is the return of serum enzyme levels to normal. Thus, it is in the mildest cases, precisely those that present the greatest diagnostic difficulty, that the serum enzymes will return to normal earliest.

Using the height of serum enzyme levels as a prognostic aid in myocardial infarction is not very satisfactory, because in severe infarction death may occur before peak serum levels may be achieved and because death or survival may depend on factors independent of the extent of the infarct (e.g. its site). Nevertheless the mortality figures clearly show that high serum levels are associated with increased mortality. Values in excess of 1000 I.U. per litre for S.L.D., 750 for S.H.B.D., and 150 for S.G.O.T. suggest a poor prognosis. The average day of sampling in the subjects studied coincided with the day on which peak values for the two former were most frequently observed, so that the figures for these enzymes were suitable for the assessment of a relation between enzyme levels and mortality.

Both S.L.D. and S.H.B.D. were free of false positive results in the 33 patients in whom a diagnosis of myocardial infarction was originally suspected but not subsequently confirmed. Three raised S.G.O.T. values were observed. Since S.G.P.T. elevation was present in 2 subjects, subclinical liver damage may well have been responsible for these abnormal values.

With the exception of one normal S.G.O.T. figure, all 20 cases of liver disease showed comparable rise in both S.G.O.T. and S.G.P.T. This was in contrast to the figures obtained in myocardial infarction where any S.G.P.T. elevation was almost always slight in comparison with the S.G.O.T. levels. A small number of these patients, however, did show a considerable rise in S.G.P.T., comparable with S.G.O.T. levels. These were thought to have sustained some degree of liver damage as a result of infarction. This was confirmed in some patients by the presence of abnormalities of liver function tests.

S.L.D. and S.H.B.D. levels were usually normal in liver disease except in the subjects with acute hepatitis. In these cases S.L.D. was raised disproportionately to increases in S.H.B.D. values, giving rise to high S.L.D./S.H.B.D. ratios. The patients with liver disease considered as a whole showed higher ratios than those observed in normal subjects and in patients with chest pain not due to myocardial infarction. Patients with myocardial infarction were found to have S.L.D./S.H.B.D. ratios on the low side of normal. 
Attention has been drawn to the value of S.L.D./S.H.B.D. ratios in the differentiation of myocardial infarction from liver disease, and it has been claimed that in myocardial infarction ratios are below 1.2 whereas in hepatic disease ratios are above 1.6 (Wilkinson et al., 1962). In the present study while ratios below 1.2 were found to favour myocardial damage and those above $1 \cdot 7$ to favour liver damage, determination of these ratios was not of clear-cut diagnostic value. It appears that this ratio can only be of limited diagnostic assistance for the following reasons.

(a) There is a wide normal range of S.L.D./S.H.B.D. ratios $(1 \cdot 13-1 \cdot 90$, mean 1.44, S.D. \pm 0.25 in a series of 46 healthy subjects studied by the author).

(b) Comparison of two enzyme procedures in the form of a ratio may exaggerate the methodological errors inherent in both.

(c) If liver damage accompanies or is the result of myocardial infarction it will mask any lowering of ratio. That liver damage may be a not infrequent accompaniment of myocardial infarction is shown by the sometimes considerable S.G.P.T. rises that may accompany S.G.O.T. increases.

(d) If the S.L.D./S.H.B.D. ratio is lowered as a result of a contribution to the serum of fastmoving S.L.D. isoenzymes, the degree of lowering on myocardial infarction will depend on the amount of fast-moving L.D. isoenzymes entering serum. Thus lowering would tend to be greatest in patients with the highest total S.L.D. activity, i.e. the more severe cases. It is however in just these severe cases that shock, with accompanying liver damage, occurs and masks any fall of ratio. Conversely in the mild cases with slight rises, and in which diagnostic difficulty may be greatest, any shift in the S.L.D./S.H.B.D. ratio may still lie within the normal range.

(e) The degree of rise in S.L.D./S.H.B.D. ratios in liver disease (elevation of slow-moving L.D. isoenzymes) will also be dependent on the total S.L.D. activity. Since large increases in the latter occurred only in acute hepatitis then it would be expected that in this condition high ratios would be observed, and this was in fact seen. In other liver diseases with normal S.L.D. or minimal S.L.D. elevation, little alteration of the ratios is to be expected, and these may remain within the normal range.

The infrequency of elevation of S.L.D. and S.H.B.D. in liver disorders, coupled with the even lesser sensitivity to liver damage of the latter, renders S.L.D. and more particularly S.H.B.D. determination of especial value in (a) the diagnosis of infarction in patients with pre-existing liver damage, and (b) the diagnosis of recurrent infarction in patients who develop liver damage either secondary to the initial infarction or as a result of anticoagulant therapy.

In these two situations S.G.O.T. and S.G.P.T. increases are usual, and are a source of diagnostic difficulty. Persistently normal S.H.B.D. levels rule out recent infarction and this finding was frequently of help in this diagnostic dilemma.

In a small number of patients studied who sustained proved recurrent infarction, the new event was found to be associated with a rise of serum enzyme levels to values of similar magnitude to those seen at initial infarction. Minor degrees of S.L.D. elevation towards the end of the second week should not necessarily be regarded as evidence of recurrence, particularly if accompanied by a disproportionately smaller degree of S.H.B.D. elevation. The results presented above suggest that such increases may be associated with ambulation. A non-cardiac origin is suggested by the absence of clinical or electrocardiographic evidence of recurrence, and the absence of a comparable rise in S.H.B.D.

\section{SUMMARY}

S.L.D., S.H.B.D., S.G.O.T., and S.G.P.T. determinations were carried out on 70 patients with myocardial infarction and on a number of patients with conditions other than myocardial infarction. The three former were almost invariably raised following myocardial infarction. Of 22 patients followed serially normal levels were achieved an average of 5.4 days following infarction for S.G.O.T., an average of 11 days for S.L.D., and 13 days for S.H.B.D. S.L.D. and 
S.H.B.D. were less frequently raised than S.G.O.T. and S.G.P.T. in the patients with conditions other than myocardial infarction, including patients with liver damage. The most prolonged rise following infarction, and the greatest freedom from false positive and false negative results was shown by S.H.B.D. The S.L.D.: S.H.B.D. ratio was of some limited help in the differentiation of myocardial from hepatic damage, ratios below 1.20 favouring myocardial injury and above 1.70 favouring liver damage.

I wish to express my thanks to Dr. B. W. Meade for his constant interest and encouragement during this study, to Professor N. F. Maclagan and Dr. J. H. Wilkinson for helpful criticism, to Drs. G. B. Hollings and W. E. Medd for permission to study their patients, and to Mrs. J. Cansfield, Mrs P. W. Foode, and Mr. M. Dunman for specimen collection and assistance with transaminase determinations.

\section{REFERENCES}

Elliott, B. A., and Wilkinson, J. H. (1961). Serum " $\alpha$-hydroxybutyric dehydrogenase" in myocardial infarction and in liver disease. Lancet, $1,698$.

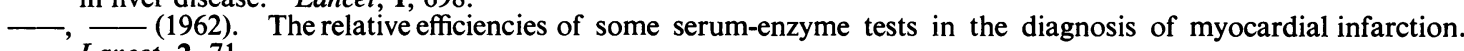
Lancet, $2,71$.

Konttinen, A. (1961). $\quad \alpha$-hydroxybutyric dehydrogenase in the detection of myocardial infarction. Lancet, $2,556$.

Pagliaro, L., and Notarbartolo, A. (1961). $\quad \alpha$-hydroxybutyric dehydrogenase in the detection of myocardial infarction. Lancet, 2, 1261.

Reitman, S., and Frankel, S. (1957). A colorimetric method for the determination of serum glutamic oxaloacetic and glutamic pyruvic transaminases. Amer. J. clin. Path., 28, 56.

Rosalki, S. B. (1961). Studies on serum and urinary enzymes. M. D. Thesis, University of London.

- , and Wilkinson, J. H. (1960). Reduction of $\alpha$-ketobutyrate by human serum. Nature (Lond.), $188,1110$.

Wieme, R. J. (1959). Application diagnostique de l'enzymo-électrophorèse des déhydrogénases de l'acide lactique. Clin. chim. Acta, 4, 46.

Wilkinson, J. H., Elliott, B. A., Cooke, K. B., and Plummer, D. T. (1962). Recognition of lactic dehydrogenase isoenzymes by starch-block electrophoresis and other means. Proc. Ass. clin. Biochem., $2,1$.

Wróblewski, F., and LaDue, J. S. (1955). Lactic dehydrogenase activity in blood. Proc. Soc. exp. Biol. (N.Y.), $90,210$.

, (1956). Serum glutamic pyruvic transaminase in cardiac and hepatic disease. Proc. Soc. exp. Biol. (N.Y.), 91, 569.

—_, Ross, C., and Gregory, K. (1960). Isoenzymes and myocardial infarction. New Engl. J. Med., $263,531$. 